\title{
El triángulo "L" en México: lectura, literatura y literacidad
}

\section{The triangle "L" in México: Reading, literature and literacy}

\author{
MARÍA TERESA OROZCo LóPEz*
}

Luis AlBERTo PÉREZ AMEZCUA*

El artículo propone una articulación de tres conceptos que han estado presentes en el discurso educativo a lo largo de los años: lectura, literatura y literacidad, a partir del concepto de lectura literaria como un pretexto para desarrollar la literacidad. La intervención se llevó a cabo en grupos de estudiantes de tres niveles educativos (primaria, secundaria y bachillerato) con quienes se trabajó con libros álbum. Se presentan los resultados parciales de esta experiencia y se plantean nuevos abordajes de la lectura y la literatura en diálogo con la literacidad que consideren la edad cronológica, la etapa lectora y el momento emotivo de cada estudiante.

The objective of this article is to propose an articulation of 3 concepts that have been in educational discourse over the years: reading, literature and literacy. It is proposed to start from the concept of literary reading as a pretext for the development of literacy through the intervention in groups of students of basic education (primary, secondary and high school) working with picture books in a contrast proposal between different educational levels. We show partial results of this experience and new approaches to reading and literature are proposed in the dialogue with literacy based on the chronological age, the reading stage and the emotional moment of each student.

\section{Palabras clave:}

lectura, literatura, literacidad, educación, México

\section{Keywords:}

reading, literature, literacy, education, Mexico

Recibido: 29 de junio de 2020 | Aceptado para su publicación: 21 de mayo de 2021| Publicado: 21 de mayo de 2021

Recuperado de: https://sinectica.iteso.mx/index.php/SINECTICA/article/view/1176 doi: 10.31391/S2007-7033(2021)0056-015

\footnotetext{
* Doctora en Humanidades y Artes por la Universidad Autónoma de Zacatecas. Profesora-investigadora en la Universidad de Guadalajara. Pertenece al Sistema Nacional de Investigadores nivel 1. Línea de investigación: lectura y literatura para niñas, niños y jóvenes. Correo electrónico: maria.olopez@academicos.udg.mx/https://orcid.org/0000-0001-5233-5409

${ }^{* *}$ Doctor en Humanidades (Literatura) por la Universidad Autónoma Metropolitana. Profesor-investigador en la Universidad de Guadalajara. Miembro del Sistema Nacional de Investigadores nivel 1. Líneas de investigación: estudios de mitocrítica cultural y estudios de literacidad. Correo electrónico: perez.amezcua@cusur.udg.mx/https://orcid.org/0000-0002-8336-7128
} 


\section{INTRODUCCIón}

i preguntáramos a los docentes -de cualquier nivel educativo en cualquier entidad federativa de nuestro país- cuál es el principal problema académico de $\checkmark$ sus estudiantes en la escuela, seguramente la mayoría responderían que las alumnas y los alumnos no comprenden lo que leen. La realidad mexicana en el tema de la lectura y la escritura en el contexto escolar no es favorecedora y los resultados en las pruebas estandarizadas nacionales e internacionales han sido (evaluación tras evaluación) poco favorables para México, como se evidencia en los más recientes resultados de México en la prueba PISA 2018, en especial en lectura:

En PISA 2018, los estudiantes mexicanos obtuvieron un puntaje bajo en el promedio OCDE en lectura, matemáticas y ciencias. En México, solo el 1\% de los estudiantes obtuvo un desempeño en los niveles de competencia más altos (nivel 5 o 6) en al menos un área (Promedio OCDE: 16\%), y el 35\% de los estudiantes no obtuvo un nivel mínimo de competencia (Nivel 2) en las 3 áreas (promedio OCDE: 13\%).

Lo anterior, a pesar de los diferentes programas, proyectos y estrategias para favorecer lo que se ha entendido como "comprensión lectora" a lo largo de varios sexenios (y diversos partidos políticos en el poder en los ámbitos federal y estatal), basados en diferentes teorías, metodologías e instrumentos, que van desde dotar (y, en muchos casos, iniciar) bibliotecas escolares y de aula, medir en las boletas la rapidez de la lectura por minuto hasta llegar a estrategias de formación continua para docentes en servicio y el programa de alerta temprana.

Este artículo plantea la idea global de entender los procesos de lectura y escritura como antecedente y sustento de la enseñanza de la literacidad resultante de la evolución teórica y epistemológica de conceptos previamente utilizados en el campo educativo, como alfabetización, lectura de comprensión o fomento lector. Nuestra propuesta radica en lo que hemos denominado triángulo "L", una manera de visualizar las relaciones socioculturales, inter- y transdisciplinarias entre los tres conceptos: lectura, literatura y literacidad.

Presentamos un panorama general del desarrollo de los enfoques teóricos que precedieron y pusieron las bases de lo que ahora entendemos por literacidad, así como las diferentes iniciativas y acciones llevadas a cabo desde los orígenes de la educación pública en nuestro país, con la creación de la Secretaría de Instrucción Pública (ahora Secretaría de Educación Pública [SEP]) hasta las más actuales modificaciones al artículo $3^{\text {o }}$ constitucional en 2019, que incluyen el concepto de literacidad por primera vez.

Nos apoyamos en este breve marco histórico y conceptual para abordar el papel del triángulo "L" (lectura, literatura y literacidad), con base en el concepto de lectura literaria, que conjunta los términos de "lectura" y "literatura", y el papel que ha desempeñado en la formación inicial de docentes en las escuelas normales y en la educación básica.

Para cerrar, formulamos una propuesta de abordaje del triángulo "L" en la educación básica a partir de una experiencia de intervención educativa en tres niveles educativos (primaria, secundaria y bachillerato). 


\section{LECTURA, LITERATURA Y ESCUELA}

La enseñanza de la lectura, la literatura y lo que hoy llamamos literacidad en México (el referido triángulo "L") ha transitado por diferentes enfoques y denominaciones a lo largo del recorrido histórico-político. Su historia se encuentra entrelazada con iniciativas de aprovisionamiento de libros y campañas de fomento lector al interior de las instituciones escolares y su estudio ha ido desde los objetivos educativos (medición de logro) hasta el desarrollo de competencias que toman en cuenta los contextos sociales para la comprensión y producción de textos (aprendizaje situado) y la inclusión de perspectivas multiculturales, de inclusión y formación ciudadana.

En cuanto a metodologías y posturas teóricas, la didáctica de la lectura y la literatura ha utilizado cartillas y silabarios durante la Colonia, algunos métodos "revolucionarios" en el Porfiriato, como el de Rébsamen, hasta el aprendizaje gramatical, las prácticas sociales de lenguaje y la inclusión de aspectos paralingüísticos y supuestos cognitivos y sociolingüísticos, que han dejado a la educación literaria como un apéndice y no como un componente significativo.

Destaca la labor llevada a cabo en los años veinte del siglo XX por la recién creada SEP bajo la dirección de José Vasconcelos y su cruzada educativa para alfabetizar a la población en la época posrevolucionaria (que era lo que se requería en ese momento sociohistórico) a través del método onomatopéyico con el cual aprendieron a leer y a escribir miles de mexicanas y mexicanos.

Más tarde se prefirieron las perspectivas lingüísticas de comprensión y producción de textos y la enseñanza de la literatura con base en el modelo historicista, que transmitía el patrimonio histórico literario del mundo, de América y de México con lecturas antológicas de obras consagradas. Esta estrategia pretendía lograr el desarrollo nacional mediante el impulso de la educación y la inclusión de literatura universal y mexicana en los libros de texto gratuitos para todos los estudiantes de nivel básico (en ese entonces entendido como escuelas primarias).

Vasconcelos logró reunir a reconocidos escritores y renombrados artistas plásticos para la edición de las Lecturas clásicas para niños; además, Gabriela Mistral seleccionó textos y editó las Lecturas para mujeres (publicadas por la SEP en 1924).

En los años ochenta del siglo pasado se empezaron a introducir y retomar métodos sintéticos, analíticos y globalizadores para la enseñanza de la lengua, que fueron la base para la introducción del constructivismo en la educación en México, y se dio un gran impulso a la distribución de la literatura para niños, niñas y adolescentes. Importantes editoriales crearon colecciones y fondos dedicados a esta población; incluso, surgieron nuevas editoriales consagradas exclusivamente a este grupo de lectores y, en 1981, se inauguró la Primera Feria Internacional del Libro Infantil y Juvenil.

Durante la reforma de 1993 para la escuela primaria, los planes y programas remitieron a la postura teórica del socioconstructivismo del aprendizaje (Piaget y Vygotsky), el cual busca potenciar el aprendizaje de los estudiantes con aproximaciones sucesivas sobre los conocimientos objetos de la enseñanza. 
Nuestra investigación retoma los trabajos del campo de la psicología genética de Emilia Ferreiro y Ana Teberosky, quienes sostienen que, sin considerar los métodos de enseñanza que el niño o la niña haya vivenciado, existe una psicogénesis de la lectura y la escritura, y como cualquier construcción cognitiva, este proceso transita por diferentes niveles y se va perfeccionando a medida que se aplica en distintos actos de escritura (Teberosky, 2000).

A nivel nacional se declaró 1999 como el "año de la lectura" y el 9 de junio de 2000 apareció publicada en el Diario Oficial de la Federación la Ley de Fomento para la Lectura y el Libro, la cual dio origen al Consejo Nacional de Fomento de la Lectura y del Libro, como parte del Consejo Nacional para la Cultura y las Artes, con carácter de órgano consultivo de la SEP.

En 2001 (sexenio de Vicente Fox, 2000-2006) se creó el Programa Nacional para el Fortalecimiento de la Lectura y la Escritura con base en el enfoque comunicativo funcional de la lengua, cuyo propósito es el desarrollo pleno de las competencias comunicativas (escuchar, hablar, leer y escribir). Su colección Libros del Rincón (biblioteca escolar y biblioteca de aula) dota a la comunidad escolar de materiales bibliográficos seleccionados por un equipo multidisciplinario, que pretende estimular y fortalecer la formación de lectores desde la escuela básica.

El discurso de las competencias en la educación surge en el contexto de las evaluaciones internacionales y la búsqueda por estandarizar procesos educativos vinculados a objetivos de crecimiento económico como un representativo de índices de calidad de vida y desarrollo.

En 2006 (sexenio de Felipe Calderón, 2006-2012) se puso en marcha la estrategia nacional $11+1$, que ofrece once estrategias para vincular la biblioteca escolar y de aula con los currículos establecidos en educación básica, al mismo tiempo que disminuye el apoyo financiero para la distribución de libros en las escuelas y va perdiendo protagonismo el proyecto Libros del Rincón.

Para el ciclo escolar 2011-2012 (sexenio de Enrique Peña, 2012-2018), la estrategia 11+1 se modificó y se convirtió en estrategia 11+5 acciones para ser mejores lectores y escritores, cuya finalidad es acercar al alumnado a la lectura con actividades mensuales organizadas en cinco líneas de acción: la biblioteca escolar, la biblioteca de aula, vinculación curricular, lectura y escritura en familia, y otros espacios para leer. Lo anterior en el contexto de la reforma educativa y lo que después se daría a conocer como el nuevo modelo educativo.

En dicha estrategia se proponen los "aprendizajes clave" que aparecen en el plan y los programas de estudio del modelo educativo para la educación obligatoria, editado por la SEP en 2017, los cuales retoman los conocimientos básicos imprescindibles sin los cuales las niñas, niños y jóvenes ven limitado su aprendizaje, a partir de la interacción del sujeto con el objeto de conocimiento.

En el inicio del periodo de Andrés Manuel López (2018-2024) se presentó, en 2019, la Estrategia Nacional de Lectura, a cargo de la Coordinación de Memoria Histórica y Cultural de México, estructurada en tres ejes: formativo (creación de hábitos de lectura), material (disponibilidad de los textos) y persuasivo (disposición colectiva hacia los productos escritos) en el contexto de la llamada "nueva escuela mexicana". 
El 15 de mayo de 2019 fue publicado en el Diario Oficial de la Federación el Decreto por el que se reforman, adicionan y derogan diversas disposiciones en materia educativa a los artículos 3ํㅜ 31 y 73 de la Constitución Política de los Estados Unidos Mexicanos, el cual establece:

Los planes y programas de estudio tendrán perspectiva de género y una orientación integral, por lo que se incluirá el conocimiento de las ciencias y humanidades, la enseñanza de las matemáticas, la lecto-escritura, la literacidad, la historia, la geografía, el civismo, la filosofía, la tecnología, la innovación, las lenguas indígenas de nuestro país, las lenguas extranjeras, la educación física, el deporte, las artes, en especial la música, la promoción de estilos de vida saludables, la educación sexual y reproductiva y el cuidado al medio ambiente, entre otras (Diario Oficial de la Federación, 2019).

Por primera vez se menciona el concepto literacidad en la Constitución y, así, comienza la obligación y el interés de los docentes por conocer acerca de este enfoque y profundizar en el concepto y sus implicaciones en el sistema educativo. A su vez, la nueva escuela mexicana, con base en sus principios, determina que el estudiantado se forme en esta propuesta:

Tienen las capacidades para lograr el conocimiento necesario en métodos y avance tecnológico para lograr el aprendizaje permanente. Propician la libertad creativa para innovar y transformar la realidad. Comprenden que las humanidades y la filosofía, las ciencias sociales, naturales y experimentales, las matemáticas, el civismo, la historia, las artes, la tecnología, la literacidad, el deporte, la salud, el cuidado del medio ambiente, constituyen factores centrales para el desarrollo integral y armónico del individuo y del país (SEP, 2019, p. 5).

El término "literacidad" es un neologismo que deriva del inglés literacy, que se traduce literalmente al español como "literacidad". La Organización para la Cooperación y el Desarrollo Económicos (OCDE) propone el concepto literacy, que ha sido traducido al ámbito hispanoparlante como "competencia”. El Programa para la Evaluación Internacional de Alumnos de la OCDE (PISA, por sus siglas en inglés), desde su primera aplicación en 2009 , señala:

El concepto de literacy o competencia se refiere a la capacidad de los estudiantes para extrapolar lo que han aprendido, y aplicar sus conocimientos y habilidades en nuevos escenarios, así como para analizar, razonar y comunicarse de manera satisfactoria al plantear, resolver e interpretar problemas en diversas situaciones del mundo real (INEE, 2010, p. 20).

La OCDE (2017) establece, desde su perspectiva, la reading literacy (competencia lectora), mathematical literacy (competencia matemática) y scientific literacy (competencia científica). Podríamos afirmar que la literacidad es la evolución de los conceptos de alfabetización, lectoescritura y lectura de comprensión, que han respondido a diferentes realidades sociales, momentos histórico-culturales y marcos teóricos (y, por ende, de entender el mundo y el ser humano). La perspectiva de la literacidad incluye en su abordaje la visión sociocultural que abre un panorama más amplio y útil para comprender las realidades del uso de los lenguajes en una sociedad en movimiento.

El uso de este término en el ámbito latinoamericano es relativamente reciente y de limitado alcance en lengua española. Al respecto, la Organización de las Naciones Unidas para la Educación, la Ciencia y la Cultura (Unesco, 2006), indica: 
Literacidad es un concepto que ha demostrado ser tanto complejo como dinámico, continuamente interpretado y definido en una multiplicidad de formas. La noción de las personas sobre el significado de ser alfabeto o analfabeto está influenciada por la investigación académica, agendas institucionales, el contexto nacional, valores culturales y experiencias personales (p. 147).

El uso del término parte de una perspectiva sociocultural en la cual es imposible separar las prácticas sociales mediadas por los textos de los elementos relacionados con la lectura y la escritura o cualquier otro sentido de aplicación del término para tratarlos independientemente de los elementos no impresos, como los valores, el contexto o el significado. En este sentido, la Unesco (2006) describe las siguientes nociones que conjuntan las posturas respecto al tema:

- Literacidad como un conjunto de habilidades individuales (enfoque desde la psicología, la lingüística y la neuropsicología). Conjunto de habilidades cognitivas de lectura y escritura adquiridas a lo largo de diferentes niveles educativos e independientes del contexto donde se desarrollan los individuos.

- Literacidad como un aprendizaje (socioconstruccionismo de Vygotsky y Piaget, y la pedagogía de la libertad de Freire) enfocado en el proceso mismo del aprendizaje antes que en los resultados. El sujeto que aprende es activo y crítico de su proceso y los entornos socioculturales que lo determinan.

-Literacidad como práctica situada (nuevos estudios en literacidad). El contexto sociocontextual es el punto importante en el desarrollo de la literacidad como práctica social.

Lankshear y Knobel (2008) proponen el término new literacies para referirse a las nuevas prácticas comunicativas de los jóvenes en la sociedad del conocimiento (que incluyen las formas de comunicarse en redes sociales), lo cual sitúa a la literacidad como centro de la política educativa a nivel mundial, pero no en América Latina, donde el auge está en las competencias. El término se traduce como alfabetismos y se define como "formas socialmente reconocidas de generar, comunicar y negociar contenidos significativos por medio de textos codificados en contextos de participación en Discursos o como miembros de Discurso" (Lankshear y Knobel, 2008, p. 74).

Por su parte, para Freire (2001), "la educación, cualquiera que sea el nivel en que se dé, se hará tanto más verdadera cuanto más estimule el desarrollo de esa necesidad radical de los seres humanos, la de su expresividad" (p. 54). Desde esta postura, el término "alfabetismo" rebasa su significado referido a la capacidad para leer y escribir y pasa a la capacidad para apropiarse de la información con independencia de cómo esta se presente.

Hablar de alfabetización de adultos y de bibliotecas populares es apuntar, entre muchos otros, al problema de la lectura y la escritura, no de la lectura de palabras y de su escritura en sí mismas, como si leerlas y escribirlas no implicara otra lectura, previa y concomitante a aquella: la lectura de la realidad misma (Unesco, 2013; Freire, 2001).

Lankshear y Knobel (2008) encuentran como alternativa el término "alfabetismo". Sin embargo, estar alfabetizado se podría interpretar en el contexto hispanohablante solo como el conocimiento básico de la lectura y la escritura y no como la 
comprensión lectora ni mucho menos como la formación de lectores y productores de textos con sentido crítico. De acuerdo con Cassany (2006), la literacidad "abarca todo lo relacionado con el uso del alfabeto: desde la correspondencia entre sonido y letra hasta las capacidades de razonamiento asociadas a la escritura" (p. 38).

La literacidad debe basarse en el concepto de que, cuando el sujeto lee, construye significaciones y sentidos en colaboración con el texto, lo cual implica asimilar (Piaget), interactuar (Vygotsky) y comprender el mundo (Freire). Debemos partir de establecer que el significado siempre está en el texto; el sujeto construye la significación o el sentido.

El acto de leer siempre es dinámico, contextual, subjetivo e institucional, y va ligado a "visiones del mundo específicas (creencias y valores) de determinados grupos sociales o culturales. Estas prácticas discursivas están integralmente conectadas con la identidad o conciencia de sí misma de la gente que las practica" (Gee, 2004, p. 24). Por lo tanto, la literacidad podría definirse como el conjunto de capacidades y habilidades para leer, comprender y asimilar lo contenido en cualquier tipo de texto (el texto y el mundo) a fin de tener la capacidad de producirlos considerando los puntos de vista y visiones del mundo tanto del emisor como del receptor. Lo anterior implica una lectura crítica y profunda y una escritura exigente y consciente de todas las dimensiones del significado de los textos que acompañan al lector.

El concepto de literacidad crítica (critical literacy), de acuerdo con Cassany y Castellà (2010), supone el dominio y el uso del código alfabético, la construcción receptiva y productiva de textos, el conocimiento y el uso de las funciones y los propósitos de los diferentes géneros discursivos de cada ámbito social, los roles que adoptan el lector y el autor, los valores sociales vinculados a estos roles (identidad, estatus, posición social, entre otros), el conocimiento que se construye en estos textos y circula en la comunidad, y la representación del mundo que transmiten.

Los nuevos estudios de literacidad son un campo emergente que reúne varias disciplinas en una relación inter- y transdisciplinar que propone a la literacidad como un continuo de habilidades, conocimientos, conductas y actitudes complejamente relacionadas e interconectadas en distintos dominios de la vida (sociales, culturales y políticos), inherentes a los procesos de lectura y escritura como herramientas esenciales requeridas para aprender en la vida y para la vida.

Por lo tanto, la literacidad como práctica social en interacción es mucho más que una competencia (entendida desde el enfoque por competencias en América Latina), ya que implica aspectos de entendimiento de significados culturales que consideran las metas y los alcances previstos por los sistemas educativos y se insertan en la vida y para la vida.

\section{EL TRIÁNGULO “L”}

Nadie podría discutir la necesidad de fortalecer la formación en lectura, literatura y literacidad de los docentes y estudiantes de educación básica y de las escuelas normales. En el contexto de la sociedad de la información y el conocimiento ya no es suficiente enseñar a decodificar y comprender el lenguaje (alfabetizar), se debe saber qué y cómo leer con sentido crítico de la realidad (literacidad), con mucho cuidado 
de cruzar la delgada línea que a lo largo del tiempo de la enseñanza-aprendizaje de la lectura se ha desdibujado entre utilizar la literatura para abordar contenidos programáticos y la formación literaria como tal, que abona al desarrollo de la literacidad de las personas.

\section{Figura. Triángulo "L"}

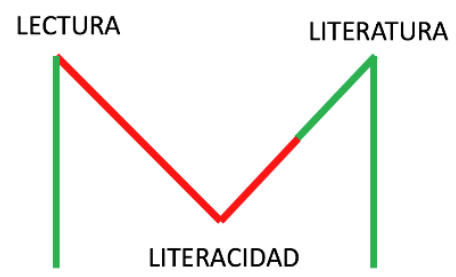

El docente se enfrenta, por tanto, a un reto de doble complejidad: cumplir con un currículo determinado que se mantiene dentro de los márgenes del canon y, además, alcanzar una de las grandes utopías de los planes educativos: el fomento de la lectura y la formación lectora, aun cuando durante su formación como docente (incluso en su trayecto como estudiante en los diferentes niveles educativos), la prioridad fue el enfoque lingüístico o comunicativo funcional de la lengua, pero no el enfoque de lectura literaria que ayuda a la formación del individuo mismo como lector empático con su realidad sociocultural.

El riesgo permanente es que se denomine "fomento lector" o "animación lectora" a cualquier actividad sin claridad en objetivos y al margen de un mediador con formación sólida y consistente en lectura literaria. El libro debe ser un medio, pero no un fin en sí mismo. Cerrillo (2013) afirma que lo anterior se ha entendido como juegos o técnicas para leer un libro determinado en vez de una actividad organizada para la promoción general de la lectura:

El mediador en lectura debe formarse a lo largo de un proceso largo, organizado, coherente y comprometido, en el que deben unirse conocimientos generales y específicos, competencias profesionales, espíritu crítico, capacidad para la intervención comunicativa, creatividad, criterios socioculturales, humanismo y, hoy también, capacidad para atender la diversidad cultural (Cerrillo, 2007, p. 90).

Lo primero que se debe tener claro es que la literatura en la escuela no debe ser tratada como un contenido de enseñanza ni mucho menos como material de lectura para abordar la enseñanza de la lengua. Se trata de perfilar una orientación que muestre la pertinencia de la experiencia literaria, y hacer explícitas las vetas interpretativas de la obra literaria para los estudiantes a través del autodescubrimiento o de epifanías (como proponía Proust, ya entrados en el argot literario). La verdadera lectura es la que se realiza de manera voluntaria; aquella que no tiene finalidad más allá de sí misma. La lectura es una decisión y, como dice Pennac (2000), "el verbo leer no tolera el imperativo. Es una aversión que comparte con algunos otros verbos: amar, soñar" (p. 11).

La lectura literaria no significa la revisión del canon literario ni conocer los enfoques de enseñanza de lengua y literatura a lo largo de su historia en la escuela. Tampoco se refiere a la historia de la literatura (la literatura como hecho cultural e 
histórico) ni a la competencia lectora (que pone el acento en los aspectos cognitivos del proceso lector). No se limita a la visión reduccionista de lo que se ha entendido como comprensión lectora (también diferente, a su vez, de la competencia lectora y literaria). La lectura literaria se interrelaciona con todos los abordajes teóricos y conceptuales mencionados que encuentran puntos de contacto e incidencia en diferentes momentos y espacios en la relación entre texto, lector y contexto específico, aunque es necesario dejar claros la diferencia y los límites conceptuales y teóricos.

La lectura literaria debe entenderse como la experiencia estética individual entre el lector y el texto literario que apela al componente emocional y a la posibilidad fáctica de que la literatura transforme al lector al desarrollar sensibilidades y habilidades para poder desentrañar la complejidad de un texto de ficción, ya sea cuento, poema o texto dramático, mediante el dominio de figuras literarias y recursos literarios, como la intertextualidad o la metaficción.

De acuerdo con Colomer (2005), para la lectura literaria "lo realmente decisivo es que la lectura resulte una experiencia personal positiva y que se realice a partir del diálogo con la obra y con la comunidad cultural" (p. 50).

La lectura literaria incluye los elementos constitutivos que exigen al lector (niño, joven o adulto) conocimientos previos de historia de la literatura, de los géneros literarios y, por supuesto, la puesta en práctica de competencias lingüísticas, gramaticales y pragmáticas y las relaciones interdisciplinarias: pedagogía, estudios del discurso, sociolingüística, lingüística aplicada, psicología y otras. Podemos hablar de lector literario como quien aborda, comprende e interpreta el texto de ficción a partir de una decisión propia, sin mediar obligatoriedad alguna. El lector literario posibilita la confluencia de significados profundos del texto en lo más interno de su ser al ponerlos en diálogo con otros textos y, sobre todo, con sus ideas y con otras personas a través de la oralidad y la escritura.

El propósito de la lectura literaria es gozar y disfrutar de la belleza de lo escrito y la satisfacción de identificar diálogos y vetas comunicantes entre el texto y uno mismo, al tiempo que habilita el diálogo con los otros (con el autor y con sus iguales) desde la postura del entendimiento y la empatía. La lectura literaria habilita al ser para comprender e interpretar el resto de discursos, porque nadie puede negar que la literatura opere por exceso.

La formación de docentes-lectores literarios se basa en ofrecer espacios (físicos, temporales y emocionales) a través de actividades de recepción para que, poco a poco, los docentes en formación establezcan su propia lectura, su interpretación e incorporen, como lo propone Larrosa (2007), la ficción en su vida diaria, con sus posibles respuestas a dudas, problemas y anhelos, y también que pongan sobre la mesa los problemas personales y sociales para crear empatía con los otros. Lo anterior coincide con la visión amplia de los nuevos estudios de literacidad en cuanto a pasar de lo universal a lo particular al estudiar las prácticas de lectura y escritura en contextos culturales específicos.

De esta manera, podríamos hablar de valoración de obras literarias cuando un lector encuentra una obra que le ayuda a entenderse a sí mismo y al mundo que le rodea, no con resúmenes y recensiones ni identificando adjetivos y sustantivos en una obra literaria, sino con vivencias y puestas en común con sus iguales a modo de tertulias dialógicas. 
La formación del docente-lector literario en diálogo con la literacidad es la habilitación para la interacción que supone el pacto de lectura entre texto literario y lector. La base de la formación literaria en la escuela debe orientarse a valorar las producciones desde el estudiante como receptor activo que coopera e interactúa con el texto. Para que la educación básica (desde preescolar hasta el bachillerato) sea el momento y el espacio para garantizar la formación en lectura literaria, se requieren docentes que sean capaces de contagiar el deseo de leer a partir de una sólida y consistente formación literaria durante su paso en la escuela normal que le habilite para conocer, elegir y sugerir lecturas con base en su propia experiencia lectora y en su itinerario como lector.

El docente no debe limitar a sus alumnas y alumnos en la interpretación de una obra literaria, para lo cual ha de tener presente que la lectura es un proceso personal, complejo, variable y abierto. Cada ser humano hace una lectura distinta de un mismo texto. Aunque todos "comprendan" por igual, en cada lector resuenan de forma diferente y con una apropiación única e íntima las significaciones y los sentimientos que el escritor pudo plasmar. Como lo establece Ballester e Ibarra (2009):

... gran parte de los lectores en edad escolar que engrosan las estadísticas más esperanzadoras consumen un determinado número de títulos por imposiciones docentes. La obligatoriedad de las lecturas, su selección de acuerdo con criterios curriculares establecidos o su explotación mediante técnicas como el comentario de textos o toda suerte de trabajos académicos, provoca en estos jóvenes lectores controvertidas actitudes en torno a la literatura y, consecuentemente, un complejo interrogante para los maestros y profesores encargados de su enseñanza (p. 26).

Algunos aspectos que se deben considerar en cuanto a la formación en lectura literaria para los futuros docentes (estudiantes normalistas) son los siguientes:

-Formación histórica y teórica acerca de la literatura para niños, niñas y jóvenes a fin de que cuenten con un panorama amplio acerca de la producción literaria y, así, visualicen los libros que pudieran servir de apoyo a su trabajo con base en la selección de obras literarias (narrativa, poesía y teatro) que se correspondan con los diferentes momentos del desarrollo lector y sus preferencias de lectura.

-Conocimiento de las tres variables en la definición del momento lector de sus estudiantes: edad cronológica (características cognitivas), etapas lectoras (habilidades lectoras) y momento emotivo (características emocionales $\mathrm{y}$ afectivas).

-Técnicas y estrategias como mediadores o mediadoras de lectura para que puedan provocar en sus estudiantes interés por la lectura, que aprecien la belleza en sus distintas formas y, en particular, en la palabra hablada y escrita.

Es importante insistir en que el docente (en formación y en activo) conozca, además de diferentes y variados textos e historias, los gustos y preferencias que tiene su estudiantado de acuerdo con la edad cronológica y el momento emotivo de cada alumna o alumno que atiende: los temas que más llaman su atención, los géneros que les atraen y el modo en que se pudieran relacionar con los momentos del desarrollo emocional. 
En los nuevos planes y programas de 2018 de la licenciatura en Educación Preescolar, que pueden ser consultados en la página web de la Dirección General de Educación Superior para el Magisterio (https://www.dgesum.sep.gob.mx), se prevén espacios curriculares para reflexionar sobre las prácticas sociales del lenguaje, su desarrollo en la infancia y las competencias lingüísticas. También, por primera vez se ofrecen los espacios curriculares denominados "Literatura infantil" y "Creación literaria".

En el caso de la licenciatura en Educación Primaria, la malla curricular del plan de 2018, en el trayecto formativo de "Preparación para la enseñanza y el aprendizaje", se inicia con un espacio curricular sobre las prácticas sociales del lenguaje, el desarrollo de la competencia lectora y la producción de textos escritos, y agrega un espacio de formación denominado "Literatura", en el cual los estudiantes pueden encontrarse con la lectura literaria; sin embargo, desde nuestro punto de vista, no es suficiente. Un docente de cualquier nivel educativo debe contar con una amplia y sólida formación literaria y lectora para poder ser ejemplo y guía para sus alumnas y alumnos.

Respecto a la licenciatura en Educación Secundaria, el plan de 2018 ofrece un rico recorrido por enfoques didácticos y lingüísticos. Debemos resaltar los espacios curriculares de formación literaria como aquellos referidos a los textos narrativos y poéticos (géneros literarios), la teoría y crítica literaria, así como la literatura universal, hispanoamericana y mexicana, que están presentes en la nueva propuesta curricular.

Esta nueva propuesta curricular no ha tenido ninguna generación de egresados y, en los tres casos -a pesar de incluir espacios curriculares específicos para la reflexión y la formación literaria sin vincularla directamente con el aprendizaje de la lengua o la lectura-, no considera el enfoque de la literacidad; por ello, es urgente y necesario armonizar los planes de estudio con la nueva legislación constitucional o aterrizar el enfoque de literacidad en los programas de estudio de cada asignatura relacionada. El triángulo "L" es aquí imperativo.

Si consideramos que los actuales docentes en formación de escuelas normales son quienes estarán al frente de los grupos de estudiantes de educación básica los próximos ciclos escolares, en los que, por mandato constitucional, la literacidad debe ser incluida en los aprendizajes de la educación básica, encontramos un desfase y una urgente necesidad de agregar estos enfoques en la formación inicial de docentes y cursos de formación continua para los profesores en servicio. Por lo anterior, resulta urgente la actualización profesional tanto de los formadores de formadores como la inclusión de este enfoque en los planes de estudios de las escuelas normales.

A partir del proyecto de investigación e incidencia en proceso apoyado por el Fondo Institucional de Fomento Regional para el Desarrollo Científico, Tecnológico y de Innovación 2019-08 denominado "Literacidad crítica: lectura literaria y escritura creativa en escuelas formadoras de docentes, comunidades de lectura en escuelas de práctica", se trabajará con estudiantes de escuelas normales públicas del estado de Jalisco para que, a su vez, el estudiantado adopte y adapte la propuesta con sus alumnas y alumnos durante el periodo de prácticas profesionales, y una vez egresados de las escuelas normales, ya como licenciados en 
Educación, puedan promover en sus escuelas con su alumnado el desarrollo de la literacidad desde el enfoque de la lectura literaria y la escritura creativa.

\section{TRIÁNGULO “L”, UNA PROPUESTA DIDÁCTICA}

El principal problema en el tema de la lectura y la literatura en la escuela radica en cómo animar a las alumnas y los alumnos para que lean fuera de la obligatoriedad de las materias escolares, y tengan en cuenta una serie de obstáculos de fondo, como el poco interés por tener presente, en primer lugar, otras alternativas de ocio, como las redes sociales, los videojuegos o plataformas de películas a la carta, como Netflix.

Colomer (2005) cita a Guercio para señalar que, en el tema de lectura, literatura y escuela, la educación básica debe considerar tres aspectos básicos de la educación literaria:

a. Conocimientos sobre los diferentes procedimientos específicos mediante los cuales la literatura da forma a la experiencia y a las ideas humanas (míticofabulosos, realísticos-miméticos, cómico-paródicos, etcétera).

b. Conocimientos sobre los procedimientos formales mediante los cuales se realizan estas formas. Es decir, algunas convenciones relativas a los géneros, la métrica, las figuras retóricas o los temas y tópicos, entre otros;

c. Conocimientos en relación con la literatura contemporánea y de pasado, de la propia lengua y de otras, sobre algunos momentos significativos e ilustrativos de conexión entre la producción literaria y el contexto sociocultural de la época (p. 51).

En la perspectiva actual, la lectura y la literatura en diálogo con la literacidad deben partir del aprendizaje situado (el aprendizaje como una práctica social como resultado de la participación en actividades colectivas que permitan la acción y la intervención reflexiva en contexto). Esta situación implica fomentar la observación, la crítica, la organización y la problematización para ser más sensibles hacia los problemas sociales y su entorno.

El desarrollo y abordaje de la literacidad en sistemas escolarizados, basados en el aprendizaje situado, debe surgir de textos que los estudiantes comprendan, que les pertenezcan a través de la apropiación, ya que, para el individuo, estos adquieren significado a partir de su realidad. Al respecto, en los diferentes grados escolares en la educación primaria (6-12 años en promedio) y secundaria (12-15 años aproximadamente) se incluye un objetivo de aprendizaje dirigido a fomentar el gusto e interés por la lectura, que puede desglosarse en tres dimensiones:

- Estimular el deseo de poseer, emplear e intercambiar libros.

- Aprender a disfrutar la lectura.

- Expresar opiniones e ideas sobre libros leídos.

Un tema fundamental en el abordaje de la lectura literaria desde la literacidad es la selección y orientación de los textos. Se debe tener especial cuidado con la definición del corpus y la tendencia didáctica a leer los clásicos (Jover y Linares, 2010), así 
como establecer y dejar muy claro que un clásico de la literatura no necesariamente debe gustarle a todas las alumnas y alumnos ni tampoco es mejor ni peor que un libro contemporáneo o uno con imágenes. Los libros clásicos y los modernos tienen el mismo propósito: ser leídos y, para la construcción de la literacidad, basta que interese al lector y enriquezca su visión del mundo.

Los libros de literatura para niñas, niños y jóvenes pueden contribuir a la formación crítica del alumnado, porque toda narración transmite una carga ideológica, que refiere a lo que Lluch (2010) conceptúa como "ideas, normas, valores, creencias, opiniones, prejuicios o actitudes próximas a la emotividad y creadas a partir de los múltiples mecanismos que permite una narración" (p. 78).

Lo más recomendable es entrar al mundo del texto escrito con la adquisición de la oralidad, la lectura en voz alta. A todos nos gusta que nos cuenten historias, sin importar nuestra edad, y para muestra están los cuentacuentos para los más chiquitos y las películas, series y novelas para los más grandes.

Es recomendable que el docente facilite el espacio para leer en voz alta dentro del aula y se dé el tiempo para escuchar las resonancias de las palabras y las historias en sus alumnas y alumnos. Permitir intervenciones y preguntas si es que el grupo así lo demanda. Ofrecer materiales cercanos a la oralidad como rimas, trabalenguas, adivinanzas y acertijos. Y, por supuesto, utilizar como base el libro álbum, en el cual el texto escrito y el visual colaboran para crear su significado en una relación interdependiente.

En este momento, el lector debe evitarse los interrogatorios largos sobre el texto y preferir explorar los personajes que le gustaron más y la razón; dibujar o crear con plastilina pueden ser otras alternativas de traducción de la experiencia lectora.

Para los lectores que comienzan a leer y que ya dominan el código escrito, se pueden ofrecer contenidos con mayor presencia de texto escrito, pero acompañados de ilustraciones. En esta etapa, son recomendables libros que tengan personajes protagónicos cercanos a los niños, niñas y adolescentes y que narren situaciones relacionadas con sus experiencias. Las temáticas que más atraen son aventuras, fantasía y humor.

Los lectores autónomos se interesan por las historias de misterios, los relatos históricos, de animales, aventuras de viajes y exploraciones, juegos, deportes, y también por los cuentos fantásticos y las leyendas. Un aspecto significativo es la construcción de criterios que les faciliten hacer elecciones individuales con base en sus experiencias de lectura previa.

Un programa general de lectura literaria en diálogo con la literacidad en la educación básica debe considerar las diferentes etapas lectoras asociadas a edades cronológicas y momentos emotivos (miedos, frustraciones, gustos y afinidades propios de una edad determinada). 
Tabla 1. Triángulo “L” y educación básica

\begin{tabular}{|c|c|c|c|}
\hline $\begin{array}{c}\text { Nivel } \\
\text { educativo }\end{array}$ & Énfasis & Líneas de trabajo & Alternativas/sugerencias \\
\hline Preescolar & $\begin{array}{c}\text { Literatura como } \\
\text { experiencia estética }\end{array}$ & Desarrollo de la imaginación & $\begin{array}{c}\text { Libro álbum } \\
\text { Lectura en voz alta } \\
\text { Adivinanzas, trabalenguas, títeres }\end{array}$ \\
\hline Primaria & $\begin{array}{l}\text { Literatura como } \\
\text { frontera del } \\
\text { lenguaje }\end{array}$ & $\begin{array}{l}\text { Las palabras creadoras de } \\
\text { mundos posibles }\end{array}$ & $\begin{array}{c}\text { Libro álbum } \\
\text { Libro interactivo } \\
\text { Juegos verbales y de acción } \\
\text { (Gianni Rodari) }\end{array}$ \\
\hline Secundaria & $\begin{array}{l}\text { Literatura como } \\
\text { discurso estético }\end{array}$ & Ficción y aventura & $\begin{array}{c}\text { Libro álbum } \\
\text { Apps y sitios web } \\
\text { Textos policiacos y de terror } \\
\text { Poesía }\end{array}$ \\
\hline
\end{tabular}

Como resultado de intervenciones sistemáticas en tres escuelas públicas (una primara, una secundaria y un bachillerato) de la zona metropolitana de Guadalajara, donde trabajamos la propuesta, podemos afirmar que los libros álbum se presentan como la mejor opción para iniciar a los estudiantes en el desarrollo de la literacidad a partir de la lectura literaria. La propuesta se fundamenta en el concepto de lectura literaria como eje para proponer la gradualidad de las actividades a desarrollar y se estructura en tres momentos:

-Primer momento: lectura compartida de un texto literario (narrativo, poético, dramático) como punto de partida de la actividad. Puede ser lectura en voz alta, técnica de cuentacuentos o lectura con apoyo de las imágenes (la técnica depende de las habilidades y destrezas de cada mediador).

-Segundo momento: charla-recuperación a partir de preguntas generadoras.

-Tercer momento: traducción de la experiencia literaria a otro tipo de lenguaje (gráfico, plástico, kinestésico). La actividad debe estar conectada con algún aspecto del texto: argumento, personajes, tiempo, espacio, ambiente, narrador o recursos literarios utilizados.

La pregunta que guía el proceso investigación e incidencia se plantea como ¿cuál es la recepción e incorporación del libro álbum en poblaciones escolares de diferentes niveles educativos? La hipótesis es que la formación de lectores literarios debe basarse en un proceso sistemático de actividades con especial atención en aspectos que habiliten al estudiantado en formas y recursos literarios más complejos.

Las diez sesiones organizadas tuvieron una periodicidad semanal y se apoyaron en libros álbum; las mismas estrategias con los mismos libros álbum se aplicaron en los diferentes niveles educativos. El énfasis varió despendiendo del nivel educativo y de la respuesta del grupo (ver tabla 2). 
Tabla 2. Textos y énfasis de cada sesión

\begin{tabular}{|c|c|c|}
\hline Texto & Énfasis & Actividad \\
\hline $\begin{array}{l}\text { Opuestoros, Sebastian } \\
\text { García Schnetzer, Libros del } \\
\text { Zorro Rojo }\end{array}$ & Lectura lúdica & Diagnóstico del grupo \\
\hline Vida de perros, Isol, FCE & $\begin{array}{l}\text { Relación entre texto } \\
\text { escrito e ilustración }\end{array}$ & $\begin{array}{l}\text { Ordenar, dar secuencia y crear una historia a partir de } \\
\text { las ilustraciones (sin texto) }\end{array}$ \\
\hline $\begin{array}{l}\text { Camino a casa, Jairo } \\
\text { Buitrago, FCE }\end{array}$ & $\begin{array}{l}\text { Relación entre ilustra- } \\
\text { ción y texto escrito }\end{array}$ & Crear una historia basada en la ilustración \\
\hline $\begin{array}{l}\text { El cochinito de Carlota, } \\
\text { David Mackee, FCE }\end{array}$ & Personaje & $\begin{array}{l}\text { Crear historia a partir del seguimiento a cualquier } \\
\text { personaje que aparece en el libro (y no es el protago- } \\
\text { nista) }\end{array}$ \\
\hline $\begin{array}{l}\text { Encuentra en esta cara lo } \\
\text { que tiene de rara, Fernando } \\
\text { del Paso, FCE }\end{array}$ & $\begin{array}{l}\text { Aspectos sonoros de } \\
\text { la lengua }\end{array}$ & $\begin{array}{l}\text { Crear una intervención de un rostro junto con una } \\
\text { rima a partir de la lectura del texto de Fernando del } \\
\text { Paso }\end{array}$ \\
\hline $\begin{array}{l}\text { Animalario universal del } \mathrm{Dr} \text {. } \\
\text { Revillod, Miguel Muruga- } \\
\quad \text { rren, FCE }\end{array}$ & Fantasía & $\begin{array}{c}\text { Crear un animal fantástico, su nombre, características, } \\
\text { hábitos y hábitat }\end{array}$ \\
\hline $\begin{array}{l}\text { Los pequeños macabros, } \\
\text { Edward Gorey, Libros del } \\
\text { Zorro Rojo }\end{array}$ & Humor & $\begin{array}{c}\text { Discutir las temáticas en los libros para niños, niñas y } \\
\text { jóvenes. Crear un abecedario del horror con el nom- } \\
\text { bre propio }\end{array}$ \\
\hline Caperucita roja & Narrador & $\begin{array}{c}\text { Alternar los narradores de la historia de Caperucita. } \\
\text { Que narre el lobo, la abuela, el cazador }\end{array}$ \\
\hline $\begin{array}{l}\text { Johana en el tren, Kathrin } \\
\text { Schärer, Océano }\end{array}$ & Metaficción & $\begin{array}{l}\text { Discutir lo que sucede en el texto al romper la barrera } \\
\text { con el lector y crear complicidad lectora. Identificar } \\
\text { este recurso en otras manifestaciones culturales (pelí- } \\
\text { culas, videojuegos) }\end{array}$ \\
\hline $\begin{array}{l}\text { Los misterios del Sr. Burdik, } \\
\text { Chris van Allsburg, FCE }\end{array}$ & Escritura creativa & $\begin{array}{c}\text { A partir del marco de ficción de las ilustraciones } \\
\text { presentadas, desarrollar una historia que justifique lo } \\
\text { que muestra la ilustración }\end{array}$ \\
\hline
\end{tabular}

La lectura literaria en diálogo con la literacidad engloba la lectura y la escritura dentro de las prácticas sociales y es entendida como la capacidad del ser humano para asimilar toda la información que percibe del contexto, de manera formal o informal, para participar y trascender en la sociedad.

Este enfoque permite analizar cómo los estudiantes construyen el conocimiento como parte de un contexto social y toma en cuenta la percepción de los estudiantes en torno a la lectura y la escritura a partir de tres ejes:

-Interpretar: acciones encaminadas a encontrar el sentido de cualquier tipo de texto.

- Argumentar: acciones relacionadas con la justificación o sustentación de la información, la explicación del porqué de las proposiciones y la sustentación de las conclusiones.

-Proponer: acciones como el planteamiento de soluciones a conflictos de tipo 
social, la generación de hipótesis y la construcción de mundos posibles derivados de la interpretación de las lecturas y su posterior reescritura.

La propuesta de lectura literaria es un camino para la formación de lectores en diálogo con la literacidad crítica que abona a la comprensión de la realidad social y tiende a la construcción de una sociedad en armonía desde la construcción de una cultura de paz.

Una aproximación lúdica a la literatura para niños, niñas y jóvenes es prioritaria en este enfoque. El estudio de la literatura como discurso estético en toda su complejidad y los fenómenos estéticos son experiencia vivida y ocasión de disfrute. La literatura debe ser el punto de partida para el entendimiento del ser humano, su historia, su contexto y sus sueños.

En un intento por hacer visibles los errores que como miembros del sistema educativo cometemos en el tema de lectura y literatura, Rodari (1997) ironiza sobre "las nuevas maneras de enseñar a odiar la literatura", entre las que señala enfrentar el libro a la televisión y al cómic, no ofrecer una elección suficiente, imponer aburridos deberes tras la lectura o culpar a los niños, niñas y jóvenes por su falta de interés hacia la lectura.

Si asociamos lectura con obligación en la escuela, existe una alta posibilidad de que estemos alejando para siempre al lector en formación de la lectura por placer, incluso por parte de quienes consideran a la literatura como fin en sí misma. De ahí la importancia de que el docente sepa combinar el estímulo, la información y la sugerencia con el respeto a la libertad y las opciones personales de la alumna y el alumno ante sus elecciones de lecturas.

De acuerdo con Rodari (1997), "hay dos tipos de niño lector, el que lee para la escuela porque es su tarea y el que lee para sí mismo, para satisfacer su necesidad de información o para alimentar la imaginación, para jugar" (p. 28). El segundo tipo de lector es el que debemos facilitar en la escuela a partir del enfoque de literacidad y considerar que los niños, niñas y jóvenes leen de una manera distinta a la de los adultos.

\section{Cierre}

La lectura literaria en diálogo con la literacidad (triángulo "L") en la educación para niñas, niños y jóvenes exige un tratamiento diferente al de una asignatura convencional. No puede reducirse a un programa de estudio para un examen, o bien, a una revisión histórica de autores y fechas, sino que debe configurarse como una actividad de múltiples facetas y aristas que suponen como prioridad el contacto y el disfrute de niños, niñas y jóvenes con las manifestaciones literarias por vía afectiva.

En este sentido, es necesario considerar la importancia de la literatura para desarrollar el conocimiento lingüístico y las habilidades comunicativas, pero no se debe limitar la experiencia literaria a esa utilidad; exige huir de todas las formas inventadas por la escuela, la administración y las editoriales para la instrumentalización de los textos literarios en función de objetivos y rendimientos académicos.

La esencia de la literatura para niñas, niños y jóvenes como auxiliar en el proceso de adquisición de la literacidad es su capacidad de proporcionar placer 
y ayudarles en el proceso de entendimiento de la lengua y sus manifestaciones simbólicas; debe ser considerada como un laboratorio del lenguaje donde el alumnado experimenta los reactivos llamados palabras y obtiene sustancias denominadas textos de creación.

La formación literaria se concibe como un proceso que incorpora la lectura de literatura a la actividad y a la comunicación en la que se articulan diversos saberes que implican la relación del lector con el texto literario, que van desde el conocimiento de las obras y sus autores hasta propiciar la adquisición de actitudes afectivas hacia la lectura de ficción.

Así, un inicio agradable está en incluir obras de la literatura para niños, niñas y jóvenes que se correspondan con las necesidades e intereses de las distintas edades para facilitar el disfrute de la lectura que se caracteriza por el respeto al niño en cuanto a temática, un abordaje literario apoyado por el uso de ilustraciones y disponibles en diferentes formatos y tipografías e, incluso, en formatos digitales y virtuales.

De esta manera, las alumnas y los alumnos lectores en formación (sin importar la edad cronológica) podrán descubrir que detrás de las palabras de ficción puede esconderse la fantasía, que en los libros no solo se atesora el saber académico (contenidos escolares), sino, sobre todo, encontrar coincidencias con sus sueños, sus miedos y anhelos, puesto que en ellos se estudia y también se juega con la creatividad al poner rostro y figura en su imaginación a sus personajes, color y forma a los paisajes, en fin, vida a la letra impresa a través de sueños vividos: la literatura como fin.

En términos estadísticos, podríamos afirmar que México es un país casi totalmente alfabetizado, pero esto todavía está muy lejos de ser literacidad. De acuerdo con los resultados de las pruebas nacionales e internacionales, más de la mitad de nuestros estudiantes de 15 años no comprenden lo que leen y no muestran interés hacia los libros y la lectura autónoma y por placer, en otras palabras, pueden leer y escribir, pero fuera del enfoque de los nuevos estudios de literacidad.

Para cerrar, dejamos abierta y sobre la mesa, para todos los docentes en activo y para los docentes en formación, una invitación a leer libros para niñas, niños y jóvenes como primer paso para autoformarse como lectores (en el caso de no serlo todavía). Nunca es tarde para iniciarse en la lectura literaria, pero debemos hacerlo con textos acordes con nuestro estadio lector, que se conforma con la intersección entre la edad cronológica, la etapa lectora y el momento emotivo de cada individuo. Hablar, leer y escribir son actos que no aprendemos solos y requieren comunidad.

\section{REFERENCIAS BIBLIOGRÁFICAS}

Ballester, J. e Ibarra, N. (2009). La enseñanza de la literatura y el pluralismo metodológico. Ocnos, núm. 5, pp. 25-36. Recuperado de http://www.revista. uclm.es/index.php/ocnos/article/view/182/162

Cassany, D. (2006). Tras las líneas. Sobre la lectura contemporánea. Barcelona: Anagrama.

Cassany, D. y Castellà, J. M. (2010). Aproximaciones a la literacidad crítica. Barcelona: Perspectiva. 
Cerrillo, P. (2013). Sobre lectura, literatura y educación. México: Porrúa.

Cerrillo, P. (2007). Literatura Infantil y Juvenil y educación literaria. Hacia una nueva enseñanza de la literatura. Barcelona: Octaedro.

Colomer, T. (2005). Andar entre libros. La lectura literaria en la escuela, México: FCE.

Diario Oficial de la Federación (2019). Decreto por el que se reforman, adicionan y derogan diversas disposiciones de los artículos 3o., 31 y 73. Recuperado de https://www.dof.gob.mx/nota_detalle.php?codigo=5560457\&fec ha $=15 / 05 / 2019$

Freire, P. (2001). Pedagogía de la indignación. Madrid: Morata.

Gee, J. P. (2004). Oralidad y literacidad: de El pensamiento salvaje a Ways with Words. En V. Zavala, M. Niño-Murcia y P. Ames (eds.). Escritura y sociedad. Nuevas perspectivas teóricas y etnográficas. Perú: Pontificia Universidad Católica del Perú. Recuperado de https://www.estudiosdelaescritura.org/ uploads/4/7/8/1/47810247/zavala_et_al_2004_escritura_y_sociedad.nuevas_perspectivas.pdf

INEE (2010). México en PISA 2009. Recuperado de https://www.inee.edu.mx/ wp-content/uploads/2018/12/Mexico-Pisa-2009-completo.pdf

Jover, G. y Linares, R. (2010). Conversar sobre libros también en las aulas. Libro Abierto, núm. 40. Recuperado de http://www.juntadeandalucia.es/educacion/webportal/sv/web/portal-libro-abierto/fomento-a-la-lectura/-/noticia/detalle/conversar-sobre-libros-tambien-en-las-aulas

Lankshear, C. y Knobel, M. (2008). Nuevos alfabetismos. Su práctica y el aprendizaje en el aula. Barcelona: Morata.

Larrosa, J. (2007) La experiencia de la lectura. Estudios sobre literatura y formación. México: FCE.

Lluch, G. (2010). Cómo seleccionar libros para niños y jóvenes. Gijón: Trea.

OCDE (2017). Marco de evaluación y de análisis de PISA para el desarrollo: lectura, matemáticas y ciencias, versión preliminar. París: Oecd Publishing. Recuperado de https://www.oecd.org/pisa/aboutpisa/ebook\%20-\%20PISAD\%20Framework_PRELIMINARY\%20version_SPANISH.pdf

Pennac, D. (2000). Como una novela. México: Norma.

Rodari, G. (1997). Un juguete llamado libro. Cuadernos de Pedagogía, núm. 36, pp. 28-31.

SEP (2019). La nueva escuela mexicana. México: Subsecretaría de Educación Media Superior. Recuperado de http://www.nuevaescuelamexicana.mx/ que-es-la-nueva-escuela-mexicana-nem/

Teberosky, A. (2000). Más allá de la alfabetización. México: Santillana.

Unesco (2013). Alfabetización y educación: lecciones desde la práctica innovadora en América Latina y el Caribe. Santiago de Chile: OREAL/Unesco.

Unesco (2006). La alfabetización, un factor vital [Literacy for Life]. París. Recuperado de https://unesdoc.unesco.org/ark:/48223/pf0000144270_spa 